\title{
Health Economic Aspects of Breast Cancer Treatment: The Compulsory Health Insurances' View
}

\author{
Barbara Zimmer Axel Heyll \\ Competence Center Oncology, Medical Services of the Compulsory Health Insurance Funds North Rhine, Düsseldorf, Germany
}

\author{
Keywords \\ Compulsory health care insurance $\cdot$ Evidence-based \\ pharmacotherapy · Breast cancer · Cost efficiency
}

\section{Summary}

Due to the impact of rising expenditures for the delivery of high-standard health care, further efforts supporting evidence-based, cost-efficient and patient-centered management in oncology are advised. This also concerns the treatment of patients with breast cancer. Reimbursement of diagnostic and/or therapeutic innovations in oncologic health care within the compulsory health insurances (CHIs) in Germany requests their evidence-based proof of benefit and medical need. Using selected examples in pharmacotherapy, recommendations to improve outpatient breast cancer care are discussed.

\section{Introduction}

Given the increasing burden of cancer worldwide, the future affordability of highly qualified cancer care, challenges and policy strategies tackle public and scientific discussions [1]. Demographic changes in western societies, expanding health care management and costs, and the introduction of mostly cost-intensive innovations are factors that exert pressure on health care funding.

Within the European Union (EU) member states, The Netherlands allocated the highest share of gross domestic product (GDP) to health in 2010 (12\%), followed by France and Germany (both 11.6\%) (European average 9\% (unweighted); USA 17.6\%) [2].

In Germany, total health expenditures (THE) rose to $€ 287.3$ billion in 2010, including costs for medical services,

\begin{abstract}
Schlüsselwörter
Gesetzliche Krankenversicherung · Evidenzbasierte Arzneimitteltherapie · Mammakarzinom · Wirtschaftlichkeit

\section{Zusammenfassung}

Angesichts der Belastungen durch steigende Gesundheitsausgaben für die Bereitstellung einer Gesundheitsversorgung auf hohem Standard sind weitere Anstrengungen zugunsten einer evidenzbasierten, wirtschaftlichen und patientenbezogenen Versorgung in der Onkologie angeraten. Dies betrifft ebenso die Behandlung von Patientinnen mit Mammakarzinom. Die Vergütung diagnostischer und/oder therapeutischer Innovationen in der onkologischen Versorgung innerhalb der gesetzlichen Krankenversicherungen (GKV) in Deutschland erfordert den evidenzbasierten Nachweis ihres Nutzens und ihre medizinische Notwendigkeit. Anhand ausgewählter Beispiele der Arzneimitteltherapie werden Empfehlungen zur Verbesserung der ambulanten Versorgung beim Mammakarzinom diskutiert.
\end{abstract}

treatment/care, goods (with $€ 46.3$ billion for drugs), and others [3, 4]. The highest amounts of cost per capita in 2008 (overall $€ 3100$ ) in relation to illnesses were allocated to cardiovascular, gastrointestinal, mental or musculoskeletal diseases and, on the 5th position, malignant neoplasms ( $€ 220$ ) $[3,5]$. In 2008 , nearly $€ 15.5$ billion were spent on health care in oncology, with $€ 1.96$ billion spent on breast cancer [3]. The total costs of malignant neoplasms in women in Germany in 2008 are outlined in figure 1 [3].

Regarding modern oncologic pharmacotherapy, especially 'targeted therapies' with monoclonal antibodies (mAbs) or thyrosine kinase inhibitors (TKIs), extraordinary growth rates in treatment costs compared to 'classical' chemotherapy are obvious. Meanwhile, 14 new TKIs as niche products are available. They require extensive mean treatment costs per year (e.g. $€ 54,364 /$ year for treatment with everolimus (Afinitor ${ }^{\circledR}$ )

\section{KARGER}

Fax +497614520714

Information@Karger.com

www.karger.com
(C) 2013 S. Karger GmbH, Freiburg

$1661-3791 / 13 / 0081-0023 \$ 38.00 / 0$

Accessible online at:

www.karger.com/brc
Dr. Barbara Zimmer MPH, MA

Kompetenz Centrum Onkologie beim MDK Nordrhein

Bismarckstrasse 43, 40120 Düsseldorf, Germany

barbara.zimmer@mdk-nordrhein.de 


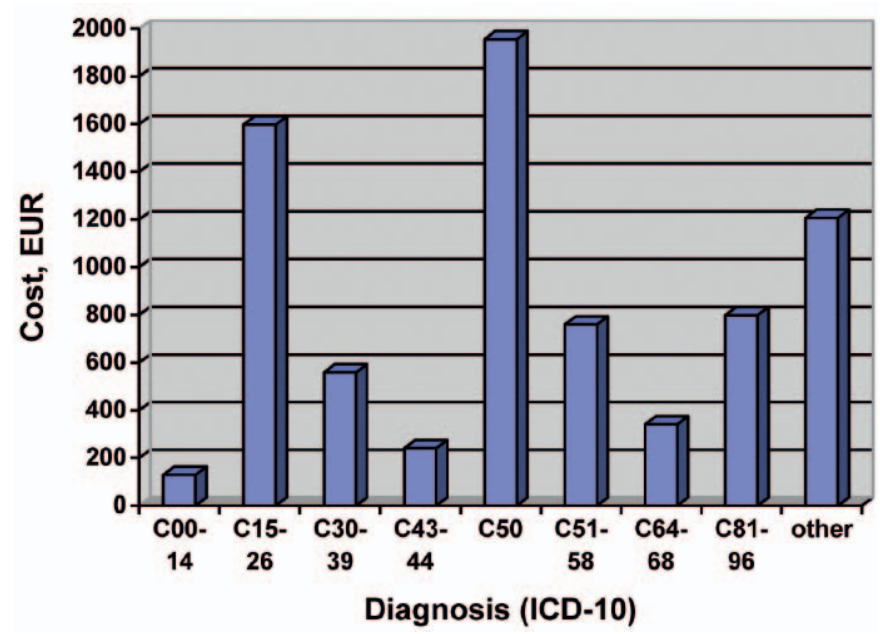

Fig. 1. Total cost of malignant neoplasms (m.n.) (defined within the codes C00-97 of the International Classification of Diseases 10 (ICD-10)) in women in Germany in 2008 (in € million): C00-14 (m.n. of the lip, oral cavity, pharynx) (129); C15-26 (m.n. of digestive organs) (1598); C30-39 (m.n. of the respiratory tract/intrathoracic) (559); C43-44 (melanoma and other m.n. of the skin) (240); C50 (breast cancer) (1956); C51-58 (m.n. of the genital organs) (760); C64-68 (m.n. of the urinary tract) (341); C81-96 (m.n. of the lymphatic/hematopoietic system and related tissues) (799); and C40-41, C45-49, C69-72, C73-75, C76-80, C97 (other malignant neoplasms) (1207). Source: According to data of the Federal Health Report [3].

or $€ 43,772 /$ year for lapatinib $\left(\right.$ Tyverb $^{\circledR}$ ), as calculated on the basis of Lauer tariffs) [6,7]. Due to their mostly rapid market access, modern drug innovations dominate the recent changes in total revenues for pharmaceuticals in oncology. Although mAbs as pharmaceutical products, like trastuzumab (Hercep$\operatorname{tin}^{\circledR}$ ), bevacizumab $\left(\right.$ Avastin $\left.^{\circledR}\right)$, or rituximab (MabThera $\left.{ }^{\circledR}\right)$, represent only $18 \%$ of all prescriptions for parenteral cancer therapeutics, they share $48 \%$ of the total revenues in 2010, as evaluated by the German Gmünder Ersatzkasse (GEK) health insurance [8].

\section{Challenges in Germany and Recent Reforms}

The solidary compulsory health insurances (CHIs) system has to assure nationwide, qualified and needs-based health care for more than 70 million insured people, while coping with rising expenditures (€ 165.6 billion in 2010 (approx. 58\% of the THE) and $€ 179.6$ billion in 2011) $[4,9]$.

Facing the population statistics that project a dramatic shrinking of the German population [10] and increasing life expectancies [4], the aging quotient (number of persons at retirement age ( $\geq 65$ years) per 100 persons in employment age (20-64 years)) will probably change from 32 to 60 in 2050 [11]. By that time, presumably $70 \%$ of all cancer patients will be 65 years and older [12]. This may cause a growing need for general support and specialized medical care, most likely with extensions of the proportional health care costs per capita [13].
With the aim to stabilize a socially responsible, cost-effective and sustainable compulsory health care funding, various legal reforms have been implemented since 2000. Amongst other fundamental revisions, the law to consolidate the competition among the CHIs (GKV-WSG) in 2007 enforced the discount obligations for the pharmaceutical industry and implemented cost-benefit evaluations for drugs ( $\$ 35 \mathrm{~b}$ Social Code Book (SGB) V). The assessment results investigated by the Institute for Quality and Efficiency in Health Care (IQWiG) [14] provide a basis for recommending appropriate drug reimbursement. In 2010, the AMNOG, a law to reform the pharmaceutical market, was enacted to abrogate the hitherto unrestricted pricing of newly market-licensed drugs with new active ingredients by the industry through implementing obligatory early benefit assessments ( $\$ 35$ a SGB V) [15]. The Federal Joint Committee (G-BA) assigns on the additional benefit of these new drugs [16], focusing on the patient-relevant additional benefit, related to the efficacy as stated in the scientific dossier, in comparison to the appropriate treatment alternative. According to the AMNOG regulations, the G-BA can also decide to take already licensed drugs within the pharmaceutical market in these benefit evaluations. The G-BA statement concerning the additional benefit determines the following pricing for $\mathrm{CHI}$ reimbursement. Extensive savings (up to $€ 2.2$ billion) are expected [17]. In 2011, health spending savings around 3.3\% for pharmaceuticals were realized due to the previously implemented legal reforms [18].

\section{Principles for Health Care within the CHI System}

The general framework conditions for statutory coverage are determined in the SGB V [19].

The German CHI system has to gain and improve the health of the insured population and, subsidiarily, to allocate health care. Its quality and effectiveness according to the approved medical scientific findings taking improvements into account ( $\$ 2$ SGB V) is mandatory. Since 2012, specified conditions in extended legal duties of CHIs to indemnify health care, as justified in defined rare, individual cases with lifethreatening or regularly lethal (or equally valued) illnesses with lack of treatment options according to the established and accepted standard, were introduced ( $\$ 2$ (1a) SGB V).

Efficiency is one of the core criteria for statutory health care. It is obligatory not only for $\mathrm{CHI}$ reimbursement but also for the health care providers and the insured population. Medical care has to be adequate, appropriate and efficient, but must not exceed the need ( $\$ 12$ SGB V).

In accordance with the SGB V, the supreme Federal Joint Committee (G-BA) plays a decisive role in the maintenance of qualified and efficient medical care within the $\mathrm{CHI}$ system. Normative regulations, as G-BA directives, define the obligatory requirements for adequate, appropriate and efficient 
health care. This can include regulations concerning the assessment and reimbursement of new health care technologies according to the approved medical scientific findings (as regu-

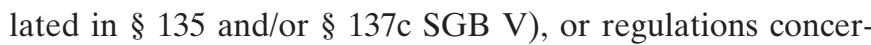
ning pharmaceuticals (cf. drug directives). Assessments of benefit and medical need of health care technologies, as commissioned by the G-BA, rely on evaluations according to the scientific principles of evidence-based medicine (EbM). They demand reliable scientific data from highly qualified clinical trials (primarily on evidence level I), proving the efficacy and risks with regard to patient-related endpoints, e.g. improvement of morbidity, mortality or quality of life, and, in pharmacotherapy assessments, benefit in reducing drug toxicities [20].

Evidence-based proof of benefit and need of treatment is a precondition to confirm efficiency. Efficiency calculations of pharmaceuticals focus on cost perspectives from the CHIs' point of view, calculating the direct costs (pharmacies' retail price), the actual arising costs for reimbursing, and, in case of pharmaceuticals with proven additional benefit in early benefit assessments, possible additional cost-benefit evaluations. When systematic evaluations assert inappropriateness or inefficiency, the exclusion of pharmaceutical treatment from $\mathrm{CHI}$ coverage is possible (as regulated in the drug directives).

\section{Off-Label Use and Import of Drugs}

\section{Off-Label Use}

Off-label pharmacotherapy is widely used in clinical practice, especially in special situations, for example in pediatric oncology. 'Off-label use is, by definition, outside the terms of the marketing authorization' defined by the European Medicines Agency (EMA) [21]. It includes treatment with regularly licensed drugs in indications that are not approved via the regulating authority. Reimbursement of individual prescription of off-label pharmacotherapy is restricted to specified conditions, as decided by the Federal Social Code (BSG) on 19 March 2002 (B1 KR 37/00 R). It allows CHI coverage only in defined cases that fulfill the following criteria:

- life-threatening or sustainable, the quality of life-defacing illness, and

- no medical alternative available, and

- if data justify the estimation that this drug will possibly gain treatment success (curative or palliative).

The last criterion requires scientific data assuming market authorization of the drug within the asked clinical indication, either because the licensing procedure is already filed or because scientific results from phase III trials (comparing the drug vs. standard or placebo) prove relevant efficacy resp. clinical benefit at justifiable risks or, outside a licensing procedure, because published data enable reliable statements concerning the quality and efficacy of the drug and expert consensus according to the benefit in terms of its application is presumed.
In addition, in rare extraordinary case situations without adequate treatment alternatives, off-label use is also indemnified within the duty of $\mathrm{CHI}$ coverage under specified conditions, as referred to in $\S 2$ (1a) SGB V [22]. Reimbursement is excluded when in-label drug prescription as adequate treatment is available.

\section{Import of Drugs}

For modern cancer-specific pharmaceuticals that need licensing via the statutory authority (EMA), successful approval is mandatory in terms of $\mathrm{CHI}$ coverage.

Due to the German Medicines Law (AMG), import of drugs that are only licensed in countries outside the relevant regulations in Germany and Europe is legally possible on the occasion of individual patients (\$73 (3) AMG). But concerning CHI coverage of case-specific imported drugs, the individual treatment situation has to satisfy additional and substantiated conditions (cf. BSG decision on 04 April 2006; B1 KR $7 / 05 \mathrm{R}$ ). This restriction has to be seen in the context of regulatory intentions to assure the safety and quality in pharmacotherapy with respect to the patient's health. Treatment with imported drugs (that may enable to expect patient-relevant benefit) is covered only in those rare cases with life-threatening situations that lack treatment alternatives, and if breaching the pharmaceuticals laws can be ruled out [22]. Reimbursement is excluded when adequate treatment with licensed drugs is available.

\section{Challenges in Breast Cancer Care in Germany}

\section{Breast Cancer Care}

Due to the rising incidence (estimating 74,500 new cases in 2012) and the high prevalence (estimating at least 249,000 cases within 5 years) [23-25] of breast cancer, attention should be paid to further strengthening evidence-based, qualified and efficient care of the patients. Although the relative overall survival (OS) rates have improved since the early 1980s, the median life expectancy for patients with metastatic breast cancer is currently still limited [26]. In Germany, a populationbased breast cancer screening program, a nationwide network of certified breast cancer units, and specialized outpatient medical services offer highly qualified oncologic management. Evidence-based S3 guidelines for early detection, diagnosis, and treatment $[27,28]$ and a disease management program for insured breast cancer patients (updated in 2011) [29] have been established.

Acknowledging the costs, the structural changes in health care delivery (e.g. reductions in mean in-hospital residence time per case), and the variety of modalities for adjuvant and palliative therapy for breast cancer, a closer look at the published evidence of newly licensed, mostly cost-intensive pharmacotherapy is reasonable. 


\section{Limited Evidence and Considerations for Clinical Care}

To illustrate the underlying questions, 2 selected examples are addressed for discussion.

Lapatinib (Tyverb ${ }^{\circledR}$ ), a kinase inhibitor, is available for the treatment of human epidermal growth factor receptor 2 (HER2)-overexpressing breast cancer in combination with capecitabine in advanced and metastatic diseases following prior therapy (including anthracyclines, taxanes, and trastuzumab in the metastatic setting), and in combination with an aromatase inhibitor for postmenopausal women with hormone receptor-positive metastatic disease, not currently intended for chemotherapy [30]. Approval was licensed in both indications with respect to efficacy data analyzed on surrogate endpoints (time to progression (TTP) or progressionfree survival (PFS)) after short periods of follow-up [31-33]. No additional benefit in OS in these combinations with lapatinib was demonstrated (except for capecitabine/lapatinib in exploratory analyses, when excluding cross-over patients) [32]. The toxicity of lapatinib is different from that of 'classical' chemotherapy, but clinically relevant [30]. Meanwhile, after concerns of the Committee for Medicinal Products for Human Use (CHMP), another application for licensing of lapatinib for treatment in metastatic breast cancer has been withdrawn [34].

In phase III trials that guided licensing of bevacizumab in defined indications in metastastic breast cancer, its efficacy in combination with chemotherapy showed significant PFS results; proof of improvements in OS and/or quality of life compared to control (chemotherapy alone) is still lacking [35, 36]. Given the palliative indication and the limitations of these results for benefit/risk assumptions, especially in unselected cases (e.g. with comorbidities, at higher age, or other conditions), the known bevacizumab-related toxicities deserve closer attention (e.g. risk of gastrointestinal perforations, hemorrhage, hypertension, and proteinuria) [35]. Overall, after bevacizumab-containing regimens (compared to chemotherapy alone), increased rates of severe arterial and venous thromboembolic events (across indications) [35, 37] and congestive heart failures (predominantly observed in patients with metastatic breast cancer) $[35,38]$ were demonstrated. Current evidence from a meta-analysis showed increased treatment-related mortality rates to the disadvantage of the bevacizumab-containing therapies [39]. Meanwhile, the US Food and Drug Administration has completely withdrawn the approval of bevacizumab for breast cancer indication [40]. Therefore, and in light of the various evidence-based proven alternatives, careful considerations concerning individual use of bevacizumab are mandatory. It can only be recommended if the patient-centered need, benefit/risk assumptions, and lack of appropriate alternatives are specifically explained.

This questions the validity of surrogate endpoints in oncology. As a result of their systematic assessments of the published literature, the IQWiG draw some basic conclusions as to the requirements for the validation of critical endpoints (e.g. recommending comprehensive data preferably from the meta-analysis of randomized clinical trials). They concluded that the validity of investigated surrogate endpoints in breast cancer is unclear [41]. According to the current evidence, PFS for the evaluation of cancer-specific pharmaceutical treatment in metastatic breast cancer cannot be accepted as a valid surrogate endpoint for OS, as has also been discussed by others [e.g. 42, 43].

At the time of reaching licence, often only limited scientific findings and proven (additional) patient-relevant benefit of drug innovations are available. Therefore, pros and cons concerning the application of newly licensed cancer-specific drugs have to be estimated on unsatisfying levels of uncertainty. Careful attention to possible limitations of trials guiding the marketing authorization is needed [44]. Further clinical trials with patient populations similar to those in daily routine care are demanded to gain comprehensive scientific knowledge about the effectiveness, the benefit, and the risk profiles, preferably in comparison to established alternative treatment standards. These issues should also be addressed within further health services research.

\section{Early Benefit Assessment}

Eribulin $\left(\right.$ Halaven $^{\circledR}$ ) is the first drug with a new active pharmaceutical ingredient with indication for the treatment of breast cancer patients that has to pass this early benefit assessment procedure since implementation of $\S 35 \mathrm{a}$ SGB V in 2011 [45]. This was done in comparison to grouped pharmaceutical alternatives as the appropriate established treatment for clinical care: (a) monotherapy with capecitabine, 5-fluorouracil, vinorelbine or (b) anthracycline- or taxane-based therapies. Based on the data from the phase III trial (EMBRACE) that compared eribulin monotherapy versus treatment of the physician's choice in the licensed indication [46] and the systematic assessments carried out by the IQWiG [47], the G-BA stated the magnitude and probability of additional benefit regarding eribulin compared to the appropriate alternatives for patients with locally advanced or metastatic breast cancer as a hint of (a) marginal additional benefit compared to capecitabine or vinorelbine monotherapy in patients who are no longer eligible for anthracyline- or taxane-based therapy, and (b) smaller in patients eligible for retreatment with anthracylines or taxanes (cf. summarizing documentation including assessments, statements of industries and associations, G-BA decision) [48]. Treatment costs per year were estimated for eribulin as around $€ 44,410$, for capecitabine or vinorelbine $€ 7430$, docetaxel $€ 29,470$, polyethylene glycol (PEG) liposomal doxorubicin € 41,510, doxorubicin € 6260, epirubicin $€ 12,190$ (for standard palliative therapy), paclitaxel $€ 27,780$, or albumin-bound paclitaxel (nab-paclitaxel) $€ 30,750$. These results, as summarized within the G-BA regulations, will influence the pricing of eribulin. Eribulin prescription in the routine management of breast cancer patients needs careful substantiation. Further head-to-head comparisons within 
phase III trials that evaluate the efficacy, risks and quality-oflife parameters are advised. Individual eligibility for retreatment with anthracycline- or taxane-based regimes or other appropriate alternatives have to consider the palliative situation of the patients.

\section{Off-Label Use, Import of Drugs, and Efficient}

\section{Pharmacotherapy in Breast Cancer}

Off-label use does happen in clinical care for patients with breast cancer. On behalf of this paper, it is impossible to comprehensively sum up the justifications of off-label prescriptions that may be individually reasonable after careful review of the medical need and the current evidence concerning in-label and off-label treatment options in distinct indications. CHI reimbursement refers to the already described obligations.

CHI coverage for breast cancer treatment with imported drugs, as restricted by the outlined conditions, is fairly justified according to the amount of alternatives available.

Improvements in resource allocation on the basis of evidence-based decisions and aiming at efficiency should be taken into account in routine clinical care. When different treatment options assuming equal benefit for the patient (under clinical and oncologic perspectives) are available, the recommended prescription decision has to be guided by its licensed indication and its efficiency. These principles prevent losses in the quality of individual care and should be considered for the case-specific adjuvant and metastatic treatment in breast cancer patients.

\section{Conclusions}

In conclusion, $\mathrm{CHI}$ reimbursement requires evidence-based treatment decisions for breast cancer patients. Proven patientrelated benefit and efficiency of treatment is mandatory within CHI coverage. Clinical trials that exceed marketing authorization and evaluate newly licensed pharmaceuticals in comparison with standard treatment alternatives with respect to patient-related endpoints are strongly recommended. They are necessary to gain further comprehensive knowledge on benefit/risk balances and to improve the quality of clinical care of patients with breast cancer.

\section{Disclosure Statement}

The authors report no conflict of interest.

\section{References}

1 Sullivan R, Peppercorn J, Sikora K, Zalcberg J, Meropol NH, Amir E, Khayat D, Boyle P, Autier P, Tannock IF, Fojo T, Siderov J, Williamson S, Camporesi S, McVie JG, Purushotham AD, Naredi P, Eggermont A, Brennan MF, Steinberg ML, Ridder MD McCloskey SA, Verellen D, Roberts T, Storme G, Hicks RJ, Ell PJ, Hirsch BR, Carbone DP, Schulman KA, Catchpole P, Taylor D, Geissler J, Brinker NG, Meltzer D, Kerr D, Aaproet M: Delivering affordable cancer care in high-income countries. Lancet 2012;12:933-980.

2 Organisation for Economic Co-operation and Development (OECD): Health at a Glance. Europe, OECD Publishing, 2012. http://dx.doi.org/ 10,1787/9789264183896-en.

3 Federal Health Report. www.gbe-bund.de.

4 Federal Statistical Office. https://www.detastatis.de

5 Robert Koch Institute (ed): Federal Health Report. Issue 48: Cost of Illness. Berlin, Robert Koch Institute, 2009.

6 Drug Commission of the German Medical Association: Afinitor ${ }^{\circledast}$ (Everolimus). www.akdae.de Arzneimitteltherapie/NA/Archiv-INN/index.html.

7 Drug Commission of the German Medical Association: Tyverb $^{\circledast}$ (Lapatinib). www.akdae.de/ Arzneimitteltherapie/NA/Archiv-INN/index.html

8 Glaeske G, Schicktanz C: Barmer GEK Drugs Report 2011;(8)

9 Association of the Substitute Health Insurances Fund (VDEK): 2011/2012 Basic Data of the Health Care System, ed 16.

10 Federal Statistical Office (ed): Demographic Development in Germany until the Year 2060. Results of the 12th Coordinated Analysis of Population Projection. Wiesbaden, Federal Statistical Office, 2009.
11 Robert Koch Institute (ed): Federal Health Report. Issue 45: Expenditure and Financing the Health Care System. Berlin, Robert Koch Institute, 2009.

12 Balducci L, Ershler WB: Cancer and aging: a nexus at several levels. Nat Rev Cancer 2005;5:655-662.

13 Federal Statistical Office: DESTATIS: Population projection. Demographic development in Germany. Issue 2: Consequence concerning hospital treatment and persons in need of care. Wiesbaden, Federal Statistical Office, 2010. https://www.destatis.de.

14 Institute for Qualitiy and Efficiency in Health Care (IQWiG): General Methods for the Assessment of the Relation of Benefits to Costs, version 1.0, 19/11/2009. www.iqwig.de.

15 Law to reform the pharmaceutical market (AMNOG; 22/12/2010). www.bmg-bund.de.

16 Drug/benefit assessment regulation (AM-NutzenV; 28/12/2010). www.juris.de

17 Federal Ministry of Health (BMG): Law to reform the pharmaceutical market (AMNOG). www.bmg-bund.de.

18 Schwabe U, Paffrath D (ed): Drug Prescription Report 2012. Updated Data, Costs, Trends and Comments. Berlin, Springer, 2012.

19 Social Code Book (SGB) V; revised in 23/10/2012. www.gesetze-im-internet.de/sgb_5.

20 Federal Joint Committee (G-BA): Code of Procedure, updated on 07/09/2012. http://g-ba.de.

21 European Medicines Agency Guidelines on Conduct of Pharmacovigilance for Medicines Used by the Pediatric Population. London, EMA, 2005 (EMEA/CHMP/235910/2005). www.ema.europa.eu/ docs/en.

22 Bücheler R, Klein A, Mohrmann M, Wink K: Aspects of drug safety in the German code of social security. Gesundheitswesen 2012;74:266-278.
23 Robert Koch Institute (ed) and Association of Epidemiological Cancer Registries (ed): Cancer in Germany 2007/2008. Berlin, RKI, 2012;(8).

24 Robert Koch Institute (ed): Epidemiology and early detection of common cancer diseases in Germany. Data and trends of the health report. GBE Compact 2012;(4). www.gbe-bund.de.

25 Robert Koch Institute (ed): Prevalance of cancer diseases in Germany. Development of prevalences from 1980 to 2010. Issues of the Federal Health Report. Berlin, Robert Koch Institute, 2010.

26 Tumorregistry Munich: Specific analyses C50: breast cancer (women). Survival post progression. www.tumorregister-munechen.de.

27 Albert U (ed): S3 Guideline Breast Cancer Early Detection in Germany, first update 2008 www.awmf.org/leitlinien/aktuelle-leitlinien.html.

28 Guideline Program Oncology, AWMF, German Cancer Society (DKG) and Deutsche Krebshilfe: Interdisciplinary S3 Guideline for Diagnosis, Therapy and Follow-up of Breast Cancer, long version 3.0, updated 2012. AWMF registry No. 032-045OL. www.awmf.org/leitlinien/aktuelle-leitlinien.html.

29 Federal Joint Committee (G-BA): DMP breast cancer (update, requirements and documentation) 17/03/2011. www.g-ba.de/information/richtlinien/ dmp/50/.

30 European Medicines Agency: EPAR - product information. Tyverb. http://ema.europe.eu (last updated 17 August 2012).

31 Geyer CE, Forster J, Lindquist D, Chan S, Romieu CG, Pienkowski T, Jagiello-Gruszfeld A, Crown J, Chan A, Kaufman B, Skarlos D, Campone C, Davidson N, Berger M, Oliva C, Rubin SD, Stein S, Cameron D: Lapatinib plus capecitabine or HER2 positive advanced breast cancer. N Engl J Med 2006;355:2733-2743. 
32 Cameron D, Casey M, Olivia C, Newstat B, Imwalle, Geyer E: Lapatinib plus capecitabine in women with HER2 positive advanced breast cancer: final survival analysis of a phase III randomized trial. Oncologist 2010;15:924-934.

33 Johnston S, Pippen P, Pivot X, et al.: Lapatinib combined with letrozole versus letrozole and placebo as first-line therapy for postmenopausal hormone receptor-positive metastatic breast cancer. J Clin Oncol 2009;27:5538-5546.

34 European Medicines Agency: Questions and answers. Withdrawal of the application for a change to the marketing authorisation for Tyverb (lapatinib). 15/03/2012. EMA/159461/2012. EMEA/ H/C/000795/II/0017. http://ema.europe.eu.

35 European Medicines Agency: EPAR - product information. Avastin. http://ema.europe.eu last updated 21 November 2012.

36 Wagner AD, Thomssen C, Haerting H, Unverzagt S: Vascular-endothelial-growth-factor (VEGF) targeting therapies for endocrine refractory or resistant metastatic breast cancer. Cochrane Database Syst Rev 2012;(7):CD008941.

37 Nalluri SR, Chu D, Keresztes R, et al.: Risk of venous thromboembolism with the angiogenesis inhibitor bevacizumab in cancer patients: A metaanalysis. JAMA 2008;300:2277-2285.
38 Choueiri TK, Mayer EL, Je Y, Rosenberg JE, Nguyen PL, Azzi GR, Bellmunt J, Harold J, Burstein HJ, Schutz FAB: Congestive heart failure risk in patients with breast cancer treated with bevacizumab. J Clin Oncol 2011;29:632-638.

39 Ranpura V, Hapani A, Wu S: Treatment-related mortality with bevacizumab in cancer patients. A meta-analysis. JAMA 2011;305:487-494.

40 US Food and Drug Administration: FDA News Release for Immediate Release: 18/11/2011, FDA Commissioner announces Avastin decision. www.fda.gov.

41 IGWiG: IQWiG Reports: Validity of surrogate endpoints in oncology. Commission No. A10-05. Translation of the executive summary of the rapid report, A10-05, version 1.1, status 21 November 2011. www.iqwig.de.

42 Wilkerson J, Fojo T: Progression-free survival is simply a measure of a drug's effect while administered and is not a surrogate for overall survival. Cancer J 2009;15:379-385.

43 Buyse M: Use of meta-analysis for the validation of surrogate endpoints and biomarkers in cancer trials. Cancer J 2009;15:421-425.
4 Schott G, Gökbuget N, Pachl H, Ludwig WD: Clinical trials in oncology. Deficits and proposals for solution. Z Evid Fortbild Qual Gesundh 2011;105:657-664.

45 Federal Joint Committee (G-BA). www.g-ba.de/ informationen/Nutzenbewertung/12/.

46 Cortes J, O'Shaughnessy J, Loesch D, Blum JL, Vahdat LT, Petrakova K, Chollet P, Manikas A, Diéras V, Delozier T, Vladimirov V, Cardoso F, Koh H, Bougnoux P, Dutcus CE, Seegobin S, Mir D, Meneses N, Wanders J, Twelves C, on behalf of the EMBRACE (Eisai Metastatic Breast Cancer Study Assessing Physician's Choice Versus E7389) investigators: Eribulin monotherapy versus treatment of physician's choice in patients with metastatic breast cancer (EMBRACE): a phase 3 open-label randomised study. Lancet 2011; 377:914-923.

47 IQWiG: Eribulin - benefit assessment referred to $\S 35$ a SGB V. Report Number 116, Commission A11-26, version 1.0, 30 January 2012. www.iqwig.de.

48 Federal Joint Committee (G-BA): Summarized documentation. www.g-ba.de/downloads/39-2611476/2010-04-19_AM-RL-XII_Eribulin.pdf. 